\title{
The importance of preoperative information for patient participation in colorectal surgery care
}

Agneta Aasa, Malin Hovbäck and Carina Berterö

\section{Linköping University Post Print}

\section{Tweet}

N.B.: When citing this work, cite the original article.

This is the pre-reviewed version of the following article:

Agneta Aasa, Malin Hovbäck and Carina Berterö, The importance of preoperative information for patient participation in colorectal surgery care, 2013, Journal of Clinical Nursing, (22), 11-12, 1604-1612.

which has been published in final form at: $\underline{\text { http://dx.doi.org/10.1111/jocn.12110 }}$

Copyright: Wiley-Blackwell http://eu.wiley.com/WileyCDA/Brand/id-35.html 


\title{
Original Article
}

Title: The importance of preoperative information for patient

\author{
participation in colorectal surgery care
}

Agneta Aasa, RN, MScN County Hospital Ryhov, Surgical Clinic, Jönköping, Sweden

Malin Hovbäck, RN, MScN, County Hospital Ryhov, Surgical Clinic, Jönköping, Sweden

Carina Berterö, RNT, MScN, PhD, Professor, Department of Medical and Health Sciences, Linköping University, Linköping, Sweden

Correspondence:

Carina Berterö, RNT, MScN, PhD, Professor

Department of Medical and Health Sciences, Division of Nursing Science BSP,

Faculty of Health Sciences, Linköping University, SE- 58185 Linköping, Sweden

Phone: +46101037768 Fax: +4613123285

E-mail: carina.bertero@liu.se 


\begin{abstract}
Aim. This study aims to identify and describe patients' experiences of a preoperative information session with a nurse, as part of the Enhanced Recovery After Surgery (ERAS) concept, and its impact on patient participation in their own care.
\end{abstract}

Background. ERAS is a standardized, multimodal treatment program for elective colorectal surgery, leading to faster recovery and shorter hospital stays via inter-professional collaboration. The ERAS concept initiated for patients a week before surgery when the patient receives detailed information about the care process during a meeting with a nurse.

Design. The study is a qualitative interpretive study based on interviews.

Method. Twelve patients, nine men and three women, were interviewed. The interviews were transcribed verbatim and analysed using interpretive phenomenological analysis (IPA).

Results. The analysis identified and formulated five themes: being seen, security, trust, responsibility and participation. All themes are closely related and illustrate positive and negative sides of the patient experience. They hang together and form a complete set of experiences; ERAS-conversation and its impact on patients’ participation.

Conclusions. The results show that patients feel confirmed in the ERAS-conversation. Healthcare professionals need to be bonding more information call during hospitalization. It is important to confirm the patient in order for them to participate and take responsibility. Reliance on caregivers is important for patients to feel safe and to participate in their own care. This study shows that the ERAS-conversation was experienced as being structured and individually tailored, but the information must apply to the patients throughout the period of care.

Relevance to clinical practice. Some shortcomings have been revealed, which should enable improvement in the care of patients. Healthcare professionals need to raise awareness of 
patients' responsibilities for participation in their own recovery and care. Healthcare professionals and patients need to be aware of each other's responsibilities.

Key words: Colorectal Surgery, Enhanced Recovery After Surgery, Interpretive Phenomenology, Preoperative Information, Participation, Recovery 


\section{Introduction}

In healthcare, routines are continuously amended and improvements in the care of patients and next of kin are continuously made. One of the areas in which improvements need to be made is the provision of information before surgery. Enhanced Recovery After Surgery (ERAS) is a standardized multimodal caring program used within colorectal surgery, which is mediated via a multidisciplinary team. Nurses who care for patients undergoing colorectal surgery have conversations with patients and their relatives in which advice that is important for patient care and recovery is provided; however, nurses lack the ability to assess patient experiences.

\section{Background}

Postoperative recovery is described as a process extending over several months, during which patients strive and struggle to return to everyday life. Even after recovery, everyday life may not always resemble what it was prior to the surgery. During hospitalization, assistance is primarily provided by healthcare professionals, who work to create optimal conditions for recovery while encouraging the patient to participate in their own care. The recovery is helped by staff listening and responding to individual needs, while motivating and helping the patient to use their own resources and capabilities (Allvin 2008).

The recovery of patients from surgery depends on both physical and psychological factors. Physical factors include the resumption of bowel function, adequate pain management and physical activity. These factors also depend on the patient's knowledge as well as the ability or courage to leave the hospital. The provision of adequate information pre- and postoperatively, as well as the experience of a safe follow-up after hospitalization, is of great importance for a shortened length of stay and avoidance of readmission (Ljungqvist et al. 2007, Varadhan et al. 2010a). Research shows that preoperative information can lead to 
better care and recovery after surgery. The patient should receive preoperative information as soon as the operation is scheduled (Kruzik 2009) because it is more likely that the patient can absorb the information before hospitalization. Many patients have difficulty understanding the given information, as it can be complicated. As such, there is a great need for personalized information. Written information complements verbal information, and enables the patient to refresh their memory of the information when needed (Walker 2007).

In a medical context, empowerment can be defined as an established relationship between a nurse and a patient in which there is a transfer of some power and control to the patient (Sahlsten et al. 2008). In terms of empowerment, nurses and patients can work together to identify the information, resources and support necessary for patients to optimize their health and acquire a sense of purpose and autonomy in their lives.

To avoid a sense of power imbalance between nurses and patients, it is important for patients to receive an explanation of why treatment is necessary before it is executed (Spence Laschinger et al., 2010). For the patient to participate actively in the process, it is important that the nurse sees the patient as an individual. Information should not be given solely by standardized procedures, but based on individual needs, combined with appropriate explanations (Eld et al., 2006).

\section{ERAS concept}

The ERAS concept aims to reduce the stress of surgical trauma, but also to support the return of important patient functions as rapidly as possible. The starting point of ERAS is that a well-informed patient copes better during the care period and feels less anxiety and pain. The patient will have a quicker recovery and shorter stay at hospital as a result. The so-called multimodal methods used in this approach are information provision, preoperative 
carbohydrate loading, minimally invasive surgery, optimal pain treatment with epidural anaesthesia pre- and postoperatively, early feeding and intensive postoperative mobilization (Basse et al. 2000, Kehlet \& Wilmore 2002, Moiniche et al. 1995, Varadhan et al. 2010a, Varadhan et al. 2010b). The information provided must be clear and precise, so that the patient can fully understand and act upon it. Patients can actively participate and influence their nutrition and mobilization. It is important that the patient is aware of what role they should play in their own recovery (Fearon et al. 2005, Varadhan et al. 2010b). One of the cornerstones of the ERAS concept is the provision of information preoperatively. This information should be given orally and in writing. The main objective is for the patient to know what will happen during hospitalization and also to understand something about the principles of the treatment. The patient receives an appointment to meet with a nurse (Fearon et al. 2005, Varadhan et al. 2010a). The appointment involves a conversation in the ward lasting for two hours, which relatives are invited to attend; the patient also meets an anaesthesiologist. During the visit, the nurse informs the patient about the three phases of hospitalization (Colorectal Gastro Team 2010). The first phase refers to the period up to the surgery and registration. The second phase refers to the day of surgery. The third phase is the recovery period after surgery up until discharge. Information is given about the objective of and the importance of mobilization, nutrition and pain management. During the stay at hospital, the patient receives a checklist of daily instructions regarding mobilization and nutrition. Information is also given in a follow-up after the patient returns home, which involves phone calls from healthcare professionals and postoperative appointments. Following the main information session, the patient receives a guided tour of the ward in order to become acquainted with the physical environment as well as the healthcare professionals working on the ward (Colorectal Gastro Team 2010). 
When the patient is dealt with in accordance with the ERAS concept, the patient's participation is strengthened and recovery is accelerated, with a shortened length of stay as a result (Fearon et al., 2005). To our knowledge, no studies have been carried out on the patient's perspective regarding the ERAS-conversation, so it is interesting to evaluate this. The primary aim of this study was to identify and describe patients' experiences of the ERAS-conversation with nurses. The secondary aim was to identify patients' participation in their own care.

\section{Methods}

\section{Design}

Since the purpose of this study is to identify and describe patients' experiences of the preoperative ERAS-conversation with a nurse, as well as its impact on patient involvement in their own care, a qualitative approach of interpretive phenomenology was chosen for this work. In this study, Interpretative Phenomenological Analysis (IPA) was used, where the researcher tries to access and interpret the patients' experiences. IPA describes each person's unique experiences as well as their common experiences. The aim is not to generalize but to examine a specific group experience. When using IPA, the researcher's own preunderstanding is recognized when it affects the interaction between the persons and the interpretation of results (Smith et al., 2009).

\section{Participants}

The sample included patients undergoing colorectal surgery at the surgical clinic of a county hospital in Southern Sweden, during the period from December 2010 to March 2011. The 
inclusion criterion was that the patients were dealt with in accordance with the ERAS concept. Another inclusion criterion was that they were able to understand and speak Swedish. A letter with information about the study and its aim and a request for participation in the study were sent to 30 patients when they had returned home after completion of the surgery. Those who wanted to participate replied to the letter and were then contacted by phone. A purposeful sample of 12 patients participated in the semi-structured interviews between 2 - 4 weeks after their surgery. Nine men and three women aged 46-73 years were interviewed.

\section{Data collection}

The data collection was conducted by qualitative interviews. An interview guide was designed and used in order to ensure that interviews remained focused on the study purpose. The interviews began with an open question: What was your conversation with the nurse like and how did the conversation affect your continued care? The interview guide consisted of three topics. They were focused on patient experiences of participation, information provision and responsibility for their own care.

Please insert the box about here

Of the 12 interviews, one was excluded as a result of poor quality of the interview material. The duration of interviews ranged from 20 to 35 minutes. The interviews were recorded and transcribed verbatim. The audio-recorded conversations were then used for the analysis (Kvale \& Brinkmann, 2009). 


\section{Analysis}

Transcriptions were made by the same person who performed the interview, shortly after the interview situation. The material was analysed step by step in accordance with Smith's analytical method IPA (Smith et al., 2009). Each interview was analysed separately. The transcribed interview was read several times in order to become familiar with the text and to create an overall impression. The first two times, the interviews were both read and interpreted in parallel. Notes were made about aspects in the interview that related to the study purpose. The notes were written with the patient's own words, for example, know in advance. On the basis of these marginal notes and the interview text, different themes emerged, which were noted in the right margin, for example, security. A theme is a recurring pattern of meaning (ideas, thoughts and feelings) throughout the text. As each transcript was analysed, several prominent themes emerged. Each of these was separately noted in order to try to find connections between the different patients’ experiences, but also to discover unique features for each person. This was done separately for each interview. During the next step of the analysis, all the prominent themes from all interviews were grouped together, so that similar themes were combined. At this step, five final themes remained. The final step in the analysis was to interpret and explain all the themes and validate them with quotes (Smith et al., 2009).

\section{Ethical approval}

All participants received both oral and written information about the study and gave their informed consent to participate. They were also assured that they could leave the study at any time and that the interview material would remain confidential at all times. The study was performed in accordance with the Declaration of Helsinki and Swedish legislation of noninvasive studies (World Medical Association 2008, Swedish Code of Statutes 2003). 
According to Swedish law ethical approval is not required for research studies conducted during advanced educational programs, but all considerations are made in accordance with ethical laws and guidelines.

\section{Results}

The analysis resulted in the identification of five different themes: being seen, security, trust, responsibility and participation. All themes are distinct but related to each other, and show different nuances of the phenomenon. The results are described in the text and illustrated with quotations from the patients.

\section{Being seen}

The patients had many questions before the surgery. Therefore, the appointment with a nurse one week before the surgery was important. It improved their outlook before admission a week later. It was perceived as better to have an in-person meeting than just to receive a letter containing relevant information. It was appreciated that there was time to ask questions in peace and quiet. The conversation helped the patients to feel acknowledged; they could see that the nursing staff was there for them. For some of the patients, it was their first contact with healthcare services, so they did not know what to ask about. These individuals, and also the others who had questions, stated that the information received was sufficient. Some patients had also experienced that too much information was given at the same time, which made it impossible to remember everything that was said. As such, it was valuable that the information was given one week before surgery, so there was time to process all of it.

"I felt taken care of in a good way; they care about what happens to you, it felt good" (I 9, raw 56-58). 
At the ERAS-conversation and before the surgery, the patient took centre stage, but during the stay in hospital, it did not feel that way. After surgery, some patients experienced that some caregivers did not listen to them and that they did not respond to their questions about the medications, surgery and any meal restrictions. At discharge, some patients experienced that they were not seen, as there was not enough time or information given to them. The follow-up phone call after hospitalization was equally important as the conversation before surgery.

\author{
"She rang when I got home... a nurse from here... of \\ course, that felt good... just because I had left, it didn't end" \\ (I 5; raw;368//374-375).
}

\title{
Security
}

The patients expressed that it was reassuring to have a meeting for the provision of information before surgery. It was important to see how the surgical department looked and to become familiar with the facilities.

$$
\begin{aligned}
& \text { "Then I got to see a bit of the ward... see what the department } \\
& \text { looks like, the rooms and amenities and everything around you, } \\
& \text { what food is served; then you know what's going to happen } \\
& \text { to you after surgery. ..." (I 4: raw; 67//70-74). }
\end{aligned}
$$

To have read the written information before the ERAS-conservation meant that the patients felt confident before this appointment and the hospital stay. They expressed that it was impossible to be more prepared.

"Just that you get the papers sent home beforehand, so you have time to consider what you need to ask about" (I 10; raw; 121-123). 
Some felt insecurity when the written information did not correspond with the verbal, such as the rules associated with purgation and surgery, and when it is appropriate to begin lifting things after surgery. Receiving information from several professionals made the patients more secure, as they were given a comprehensive picture of the entire process. It was important to know what the days before and after surgery would be like, so they could envision how it would be and understand the meaning of what would be done. The patients expressed that it was reassuring to know how much time things would take and how long the expected length of stay was. The ERAS-conversation a week before surgery gave them a clear understanding of what lay ahead.

$$
\begin{aligned}
& \text { "She was of course talking about how everything would work } \\
& \text { and generally speaking it was correct" (I 6, raw; 10-13). }
\end{aligned}
$$

By being well informed and thus prepared, the patients could question if something mentioned during the information session was not accomplished during the period of care. This made them feel secure. The patients perceived the information of the conversation differently, depending on what they focused on. Some perceived that the information was just about the period before surgery, while others felt that it was all about pain relief. In this regard, the patients experienced a sense of security in the areas that they had particularly focused on.

The patients in this study felt safe by having a family member by their side during the information session. This was because it was valuable to discuss the given information at home afterwards. 


\section{Trust}

The ERAS-conversation made the patients feel calm before the treatment. It was stated that, after the session, it felt less frightening and threatening to be admitted to hospital. The patients felt cared for and had confidence in the staff. They expressed that the nursing staff was competent, that they knew what they were doing.

"I feel like this is routine for you and of course it is, but it's a big deal for me as I have never been through this before; as such, it's incredibly important that you feel that you come to skilled people who will take care of this when it's really important " (I 9, raw; 125-130).

There was a concern about not being in control of the situation when it came to the surgery. By having the opportunity to speak with several professionals, the patients' confidence in the healthcare system was strengthened and they felt a sense of control.

Some felt doubt and uncertainty about what the staff told them, including that they would be able to eat and move around immediately after surgery. As the staff explained how this was possible and why it was so important, it became easier to trust the information and have confidence in the caregivers. The explanations made the patients do things they would not otherwise have done.

"I think I trusted them totally there... I was up and walking a little bit even though it was hard; they did explain to me why I should do it” (I 12, raw; 61-62//67-68).

The patients considered that it was valuable when the staff could contribute to a positive feeling; the operation would go well and each subsequent day would. 


\section{Responsibility}

Many patients were aware of their responsibilities and did what they were required to do before, during and after hospitalization. They knew it was important to be responsible, and stated that they knew that they could not just expect to get everything, but that everyone was responsible for a good result. Although it was hard owing to pain or a poor appetite, among others, they did what they had to do.

"You knew you should try as soon as possible to get out of bed, preferably on the same day as you are moved to the ward...

It felt important to try to live up to that" (I 4; raw, 97-100//137).

Patients expressed the view that their own efforts to hasten recovery were influenced by the information session, and that they were thereafter determined to become active in their own recovery. The patients took responsibility for their recovery by setting their own targets for the days after surgery. Several of them said that they did everything they were told to do, but one thought it was important to develop her own ideas and thoughts, and not to be passive and just put herself in someone else's care. It was useful to have information on paper during the hospital stay, as the patients were reminded of what was to be done and they could take responsibility for what was planned.

"Good to have it on paper as well, to keep an eye on what I have to do now. Not being able to follow it to the letter, that's a different matter, but I could strive for it anyway" (I 2: raw;135-136).

One patient did not think that the information session with a nurse and the hospital stay were related. Much information that was given during the meeting was not followed up by the medical staff during hospitalization; it was as if they were unrelated. This patient also thought that it was difficult to remember, during the hospital stay, everything that had been 
said during the ERAS-conversation. It was felt that the nursing staff should have reconnected more to the information session during hospitalization. They should have verified that the patient did what had to be done, as the nursing staff has the greatest responsibility for patient care.

"I am an adult who must take responsibility myself, but it just didn't happen... nutritional drinks, them I could take myself, but I did not. Who has the overall responsibility to check that the patients do what they're supposed to do?" (I 11; raw; 315-316//320-322).

\section{Participation}

The patients were involved in their own care by actively participating and performing certain actions before, during and after hospitalization. Before they were admitted, they could for example use the anticoagulant syringe themselves. During hospitalization, many patients were involved by completing their checklists on food intake and mobilization.

"In the beginning, the nursing staff wrote down what I ate and how much I drank... but then I filled it in myself" (7; 151-152).

Some patients expected to be more involved in their care after attending the ERASconversation. These patients never filled in their checklist that was lying on the bedside table, but felt that it was not important to be involved in this because the staff never asked if the checklist had been followed. After the ERAS-conversation, the patients knew what would happen during the postoperative period; they stated that the need for participation in their own care became self-evident.

One patient took the initiative himself to get out of bed in the evening after surgery, without any medical staff suggesting it. 
"Nobody told me in the evening when I came up from

surgery... get up and try to move around... but it was more

like you asked, 'How do I remove this... so I can get out of bed'"

(I 5; raw; 173-176).

Many patients felt that they were involved when they performed their activities, while one said that participation was about expressing their needs to the care staff. By having a relative attending the information session, the patients experienced that they could both be involved in the patient's recovery after discharge.

All themes presented above are related to each other and illustrate positive and negative aspects of the patients' experiences. They show different facets of the phenomenon, which together form a whole experience; they reveal various aspects of the ERAS-conversation and its potential impact on length of stay in hospital.

\section{Discussion}

In this study, to achieve a deep understanding of patients’ experiences, an approach using interpretive phenomenology was chosen, which explores the personal experience of an event. The advantage of IPA is that it is an open approach that may lead to new knowledge (Smith et al., 2009). To our knowledge, the importance of an information session in the ERAS concept has not been described in reports on previous qualitative studies.

Our results show that the ERAS-conversation with a nurse is important for patient participation and their ability to take responsibility for their own actions. The information 
session makes patients feel acknowledged by medical staff. In this study, the patients experienced that they took centre stage during the information session. However, during hospitalization, some patients felt like they were just one among many, which inhibited their participation. It is important for the actions of healthcare professionals during a hospital stay to correspond with the information provided during a preoperative ERAS-conversation. Otherwise, the information will not be perceived as important and the patient will not be optimally involved in their own care and recovery. The importance of listening and being responsive to individual patient needs has been confirmed in another study (Allvin 2008), as well as spending enough time with a patient (Beaver et al., 2005).

The patient in our study stated that it was of great value to hear that they would feel better the next day and also to have goals for the day: to have something to strive for. Focus on a goal promotes participation. Sahlsten et al. (2009) stated that close collaboration with a patient, as well as a desire to know a patient, are required for stimulating and optimizing the patient's participation. It is also important to strengthen the patient's self-care capacity by motivating and focusing on identified targets (Sahlsten et al., 2009). Positive feedback is important in patient participation, and support of nursing staff can be crucial in the patient's recovery (Norlyk \& Harder 2009).

Our results show that the patients' perception of involvement differed. Some felt involved when they were expressing their needs, while others argued that they were involved when they were taking part in their own nutrition and mobilization. Healthcare professionals need to be aware that the experience of participation varies among patients and that it is important to listen to patients (Eld et al., 2006).

After attending the ERAS-conversation, the patients were aware of their responsibilities during the hospital stay and generally performed certain actions as required. One patient took 
no responsibility at all, and instead stated that the healthcare professionals should take all responsibility, telling patients when every action should be performed. This inhibited the patient's participation. When nobody reminded or directed this patient, it was perceived as unimportant to do the actions. However, it takes courage for a patient to take responsibility. Healthcare professionals must focus on the patient and have an insight into the patient's insecurities in order to strengthen the patient's sense of responsibility (Norlyk \& Harder 2009). We are certain that healthcare professionals need to encourage and acknowledge patients throughout the treatment period and be aware of this uncertainty felt by patients. This may be an explanation as to why the patients do not always follow the given directions.

The patients in this study felt that information from several different professionals strengthened their confidence in the staff. Being dealt with in accordance with the ERAS concept gives the patient confidence, since the concept is perceived as structured (Norlyk \& Harder 2009). Our results show that, when the staff explained why the procedures should be performed, trust was created. The patients then performed the actions, even if they were reluctant. By explaining why they should carry out certain actions, the participation was strengthened (Spence Laschinger et al., 2010). Having confidence in the medical staff during a period of care will affect whether a patient will follow the given information and is crucial for the patients’ participation.

After surgery, the patients expressed that it was difficult to remember the information given during the information session. They stated that they mainly focused on how the surgery had gone. Allvin (2008) stated that the information needs to be repeated during the hospital stay. It is beneficial for recovery if the proposed plan is accomplished. It is detrimental for the patient's recovery to receive conflicting information. This is consistent with what the patients in this study experienced; they expressed that it was reassuring when the check-list was followed. Some also felt that they were given mixed messages, both orally 
and in writing, which created a sense of insecurity.

It was important that the information session was held one week before surgery, as the patients' perception was that a large amount of information was received, which needed to be processed. This is consistent with the findings of another study (Mitchell 2007). Being able to get acquainted with the premises and staff and to prepare oneself by reading the written information before the information session and before being admitted gave a sense of security. Our results show that the patients had different views of what the information session was about. Even though they received the same information, one patient said that the information was about pain relief, while another thought it was about what would happen before the operation. It is important to be sensitive to what each patient needs to know and to provide individual but structured information. Mitchell (2007) also stated that patients who are about to undergo surgery focus on what is to come, rather than the given information. The ERAS-conversation and its structure allow the patient to be well informed about the care process and prevent any details from being lost. The patients' different views on what this session was mostly about depended on their attitudes. That does not have to be negative for the patient, as it still feels personal. The individual information is decided by the patient's needs. Because of the structure of the information session, those without experience of receiving healthcare obtained information about the entire care process.

During the hospital stay, the patients read the written information to refresh their memories and could thus take responsibility for what was planned. They could also see if the nursing staff would deviate from the schedule. Walker (2007) confirmed that the written information is used for updates.

Our results also show that the patients did not feel seen at discharge; not enough time or information was given to them. It was confirmed by a previous study that too little information is given to patients who have undergone abdominal surgery (Williams 2008). In 
the present study, the follow-up phone call was perceived by the patients as being just as important as the preoperative information session. The nurse is an important contact who provides care, information and support, and also coordinates the patients' care before and after surgery, which may reducing the patients' feelings of insecurity and fear (Jonsson et al., 2010).

One limitation of this study could be said to be the small number of patients. In phenomenological studies, $15 \pm 10$ informants is considered an acceptable number (Kvale \& Brinkmann, 2009). The interviews also appeared to be rich and substantial in depth and variation of reported experiences of ERAS.

Another limitation could be that some of the authors were familiar with the ERAS concept, which could have affected their interpretations. This was compensated for by one of the authors not being involved in clinical work or the ERAS concept, but instead being skilled in qualitative research. The authors, who all were involved in analysing the interviews, varied in terms of their knowledge and experiences. The results have been presented with quotes from the patients. The quotes strengthen the quality and validity of the study (Smith et al., 2009).

\section{Conclusion}

The results of this study show that the patients felt that they were the focus of attention during the information session. Healthcare professionals need to improve the correspondence between the ERAS-conversation and the actual activities during hospitalization. It is important to acknowledge the patient, in order to make them participate and take responsibility for their own care. For many patients, being cared for in a healthcare environment is a new and unfamiliar experience. The information session, provided 
preoperatively by a nurse, gives security by preparing the patients for what is going to happen and giving them the opportunity to familiarize themselves with the environment. Trust in healthcare professionals is important for patients to feel safe and to be willing to participate in their own care. It is crucial for patient participation to receive information about why certain actions should be carried out. As the information provided at discharge may be insufficient, a follow-up phone call a week after discharge is also important for patients. The results in this study show that the ERAS-conversation is experienced as being structured and individually tailored; however, the information must follow the patients throughout the entire care period, which does not seem to be the case at present.

\section{Relevance to clinical practice}

Our results demonstrate the shortcomings that the patients experienced. These shortcomings have been revealed, which should enable improvement in the care of patients. Healthcare professionals need to raise awareness of patients' responsibilities for participation in their own recovery and care. Healthcare professionals and patients need to be aware of each other's responsibilities. 


\section{Contributors:}

Study Design (AA, MH, CB)

Data Collection and Analysis (AA, MH, CB)

Final approval of the version to be published. (Author $A A, M H \& C B$ )

Acknowledgements:

We are grateful to all patients participating in our study, sharing their experiences with us.

We are also grateful to the Division of Nursing Science at the Department of Medical and

Health Sciences for financial support.

\section{Conflict of interest:}

None of the authors have any conflicts of interest or financial disclosures in relation to this manuscript or the work described in this manuscript 


\section{References}

Allvin, R.E., M. Rawal, N. Idvall, E. 2008. Experiences of the postoperative recovery process: an interview study. Open Nursing Journal 2, 1-7.

Basse, L., Hjort Jakobsen, D., Billesbolle, P., Werner, M. \& Kehlet, H. 2000. A clinical pathway to accelerate recovery after colonic resection. Ann Surg 232, (1) 51-57.

Beaver, K., Jones, D., Susnerwala, S., Craven, O., Tomlinson, M., Witham, G. \& Luker, K.A. 2005. Exploring the decision-making preferences of people with colorectal cancer. Health Expect 8, (2) 103-113.

Eldh, A.C., Ekman, I. \& Ehnfors, M. 2006. Conditions for patient participation and non-participation in health care. Nursing Ethics 13, (5) 503-514.

Fearon, K.C., Ljungqvist, O., Von Meyenfeldt, M., Revhaug, A., Dejong, C.H., Lassen, K., Nygren, J., Hausel, J., Soop, M., Andersen, J. \& Kehlet, H. 2005. Enhanced recovery after surgery: a consensus review of clinical care for patients undergoing colonic resection. Clinical Nutrition 24, (3) 466-477.

Garretson, S. 2004. Benefits of pre-operative information programmes. Nursing Standard 18 (47) 3337.

Grönnestad, B.K. \& Blystad, A. 2004. Patients' experience with information in connection with an operation -- a qualitative study. Nordic Journal of Nursing Research \& Clinical Studies / Vård i Norden 24 (4) 4-8.

Jonsson, C.A., Stenberg, A. \& Frisman, G.H. 2010. The lived experience of the early postoperative period after colorectal cancer surgery. European Journal of Cancer Care (Engl.) 20, (2) 248-256.

Kehlet, H. \& Wilmore, D.W. 2002. Multimodal strategies to improve surgical outcome. American Journal of Surgery 183, (6) 630-641. 
Kent, E. 1998. Preoperative teaching: the role of the surgical nurse? British Journal of Theatre Nursing 8, (7) 34-36.

Keulers, B.J., Scheltinga, M.R., Houterman, S., Van Der Wilt, G.J. \& Spauwen, P.H. 2008. Surgeons underestimate their patients' desire for preoperative information. World Journal of Surgery 32, (6) 964-970.

Colorectal Gastro Team (Kolorektala gastroteamet). 2010. Lokalt PM för Eras patienter (Kirurgkliniken Länssjukhuset Ryhov, Jönköping). In Swedish.

Kruzik, N. 2009. Benefits of preoperative education for adult elective surgery patients. AORN Journal 90,(3) 381-387.

Kvale S. \& Brinkmann S. Interviews: learning the craft of qualitative research interviewing. London: Sage; 2009.

Larsson, I.E., Sahlsten, M.J., Segesten, K. \& Plos, K.A. 2011. Patients' perceptions of barriers for participation in nursing care. Scandinavian Journal of Caring Science 25, (3) 575-582.

Lindwall, L., von Post, I. \& Bergbom, I. 2003. Patients' and nurses' experiences of perioperative dialogues. Journal of Advanced Nursing 43, (3) 246-253.

Lithner, M. \& Zilling, T. 2000. Pre- and postoperative information needs. Patient Education Counselling 40, (1) 29-37.

Ljungqvist, O., Hausel, J., Nygren, J., Thorell, A. \& Soop, M. 2007. Preoperative patient preparation for enhanced recovery after surgery. Transfusion Alternatives in Transfusion Medicine 9, (1) 4549.

Mitchell, M. 2007. Psychological care of patients undergoing elective surgery. Nursing Standard 21, (30) 48-55; 58, 60. 
Mohn, A.C., Bernardshaw, S.V., Ristesund, S.M., Hovde Hansen, P.E. \& Rokke, O. 2009. Enhanced recovery after colorectal surgery. Results from a prospective observational two-centre study. Scandinavian Journal of Surgery 98, (3) 155-159.

Moiniche, S., Bulow, S., Hesselfeldt, P., Hestbaek, A. \& Kehlet, H. 1995. Convalescence and hospital stay after colonic surgery with balanced analgesia, early oral feeding, and enforced mobilisation. European Journal of Surgery 161, (4) 283-288.

Norlyk, A. \& Harder, I. 2009. After colonic surgery: The lived experience of participating in a fasttrack programme. International Joural of Qualitative Studies on Health and Well-being 4, 170180.

Pritchard, M.J. 2009. Managing anxiety in the elective surgical patient. British Journal of Nursing 18, (7) 416-419.

Sahlsten, M.J., Larsson, I.E., Plos, K.A. \& Lindencrona, C.S. 2005. Hindrance for patient participation in nursing care. Scandinavian Journal of Caring Science 19, (3) 223-229.

Sahlsten, M.J., Larsson, I.E., Sjostrom, B. \& Plos, K.A. 2008. An analysis of the concept of patient participation. Nursing Forum 43, (1) 2-11.

Sahlsten, M.J., Larsson, I.E., Sjostrom, B. \& Plos, K.A. 2009. Nurse strategies for optimising patient participation in nursing care. Scandinavian Journal of Caring Science 23, (3) 490-497.

Smith, J.A. 2007. Qualitative psychology : a practical guide to research methods. London: SAGE.

Smith, J.A., Flowers, P. \& Larkin, M. 2009. Interpretative phenomenological analysis: theory, method and research. Los Angeles: Sage.

Socialstyrelsen. 2007. Nationella riktlinjer för kolorektalcancersjukvård : medicinskt och hälsoekonomiskt faktadokument (National Guidelines for Colorectal Cancer Care) [Electronic resource, accessed October 06, 2010] http://www.socialstyrelsen.se/NR/rdonlyres/96F650D3FE76-45B9-8715-DDCCC680C6CF/7266/20071024.pdf. In Swedish. 
Swedish Code of Statutes. The act concerning the ethical review of research involving humans (SFS 2003:460). 2003. Available from http://www.epn.se/start/startpage.aspx [accessed 7 September 2010].

Spence Laschinger, H.K., Gilbert, S., Smith, L.M. \& Leslie, K. 2010. Towards a comprehensive theory of nurse/patient empowerment: applying Kanter's empowerment theory to patient care. Journal of Nursing Management 18, (1) 4-13.

The Health and Medical Service Act. (1982:763). Available from: http://www.sweden.gov.se/content/1/c6/02/31/25/a7ea8ee1.pdf Accessed 12 November 2010

The National Board of Health and Welfare (2005) Description of Competency for Registered Nurse No: 2005-105-1. The National Board of Health and Welfare, Stockholm. Available at http://www.socialstyrelsen.se/Lists/Artikelkatalog/Attachments/9879/2005-105-1_20051052.pdf

The National Board of Health and Welfare (2008). "Statistical database: cancer statistic. Available at http://192.137.163.49/sdb/can/val.aspx." Accessed 6 October, 2010

Thompson, J.S., Baxter, B.T., Allison, J.G., Johnson, F.E., Lee, K.K. \& Park, W.Y. 2003. Temporal patterns of postoperative complications. Archive of Surgery 138, (6) 596-602; 602-593.

Walker, J.A. 2007. What is the effect of preoperative information on patient satisfaction? British Journal of Nursing 16, (1) 27-32.

Varadhan, K.K., Lobo, D.N. \& Ljungqvist, O. 2010a. Enhanced recovery after surgery: the future of improving surgical care. Critical Care in Clinic 26, (3) 527-547, x.

Varadhan, K.K., Neal, K.R., Dejong, C.H., Fearon, K.C., Ljungqvist, O. \& Lobo, D.N. 2010b. The enhanced recovery after surgery (ERAS) pathway for patients undergoing major elective open colorectal surgery: a meta-analysis of randomized controlled trials. Clinical Nutrition 29, (4: 434440. 
Wasey, N., Baughan, J. \& de Gara, C.J. 2003. Prophylaxis in elective colorectal surgery: the cost of ignoring the evidence. Canadian Journal of Surgery 46, (4) 279-284.

Williams, B. 2008. Supporting self-care of patients following general abdominal surgery. Journal of Clinical Nursing 17, (5) 584-592.

World Medical Association. Medical Association Declaration of Helsinki - ethical principles for medical research involving human patients. 2008. Available from http://www.wma.net/en/30publications/10policies/b3/index.html [accessed 06 October 2010] 